Introduction To benefit symptomatic patients with moderate-tosevere COPD not managed by single bronchodilator, COPD management strategies recommend combining bronchodilators with different mechanisms. We compared, once-daily dual bronchodilation by co-administration of the long-acting muscarinic antagonist (LAMA) glycopyrronium 50 $\mu$ g (GLY) and the long-

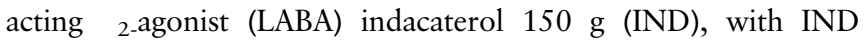
$150 \mu \mathrm{g}$ monotherapy.

Methods In this randomised, multicentre, placebo-controlled, double-blind, parallel-group study, patients with moderate-tosevere COPD were administered with GLY + IND or IND + placebo $\left(1: 1\right.$; all delivered via Breezhaler ${ }^{\circledR}$ device) for 12 weeks. We assessed lung function, dyspnoea (via the transition dyspnoea index [TDI]), patient-reported symptoms, and safety and tolerability over 12 weeks.

Results Of the 449 patients randomised (GLY + IND $[\mathrm{n}=226]$; IND $[\mathrm{n}=223]), 94.0 \%$ completed the study. At Week12, GLY + IND demonstrated a statistically significant improvement in mean trough forced expiratory volume in one second $\left(\mathrm{FEV}_{1}\right)$ over IND (least squares mean treatment difference [Td]: $64 \mathrm{~mL} ; \mathrm{p}<0.001)$. Significantly greater improvements in $\mathrm{FEV}_{1}$ area under curve from $30 \mathrm{~min}$ to $4 \mathrm{~h}\left(\mathrm{FEV}_{1} \mathrm{AUC}_{30 \mathrm{~min}-4 \mathrm{~h}}\right)$ and trough forced vital capacity were observed with GLY + IND vs IND on Day1 (Td: $105 \mathrm{~mL}, 112 \mathrm{~mL}$, respectively) and at Week12 (Td: $111 \mathrm{~mL}, 93 \mathrm{~mL}$, respectively), all $\mathrm{p}<0.01$. GLY + IND demonstrated significant improvements in inspiratory capacity versus IND at most timepoints on Day1 and Week12 (Td: 59 to $159 \mathrm{~mL}$ ). GLY + IND significantly improved TDI total score versus IND (Td: $0.49, \mathrm{p}=0.037)$ and a higher proportion of patients on GLY + IND achieved a clinically meaningful improvement ( $\geq 1$ point) versus IND at Week12 (odds ratio 1.97 favouring GLY + IND; $p=0.004)$. GLY + IND was also associated with significantly greater improvements in mean daytime respiratory symptom score and the percentage of days being able to perform usual daily activities vs IND over 12 weeks of treatment (Td: -0.1 and 6.2, respectively; both $\mathrm{p}<0.05$ ). The overall incidence of adverse events (AEs) and serious AEs (SAEs) was comparable for the GLY + IND and IND groups (AEs: $37.6 \%$ vs $34.1 \%$; SAEs: $2.2 \%$ vs $2.3 \%$, respectively).

Conclusion In patients with moderate-to-severe COPD, compared with indacaterol monotherapy, once-daily co-administration of glycopyrronium and indacaterol delivered via Breezhaler ${ }^{\circledR}$ device provided superior improvements lung function and early post-dose bronchodilation (from Day1), dyspnoea, symptoms and activities, without adversely affecting safety and tolerability.

\section{P233 EFFICACY AND SAFETY OF ONCE-DAILY GLYCOPYRRONIUM COMPARED WITH BLINDED TIOTROPIUM IN PATIENTS WITH COPD: THE GLOW5 STUDY}

${ }^{1} \mathrm{KR}$ Chapman, ${ }^{2} \mathrm{~K}$ Beeh, ${ }^{3} \mathrm{ED}$ Bateman, ${ }^{2} \mathrm{~J}$ Beier, ${ }^{4} \mathrm{AD}$ D'Urzo, ${ }^{5} \mathrm{R}$ Nutbrown, ${ }^{6} \mathrm{H}$ Chen, ${ }^{6} \mathrm{M}$ Henley, ${ }^{5} \mathrm{~T}$ Overend, ${ }^{6} \mathrm{P}$ D'Andrea; ${ }^{1}$ Toronto Western Hospital, Toronto, Canada; ${ }^{2}$ Respiratory Research Institute, Wiesbaden, Germany; ${ }^{3}$ University of Cape Town, Cape Town, South Africa; ${ }^{4}$ University of Toronto, Ontario, Canada; ${ }^{5}$ Novartis Horsham Research Centre, Horsham, UK; ${ }^{6}$ Novartis Pharmaceuticals Corporation, East Hanover, NJ, USA

\subsection{6/thoraxinl-2013-204457.385}

Background Glycopyrronium, a once-daily long-acting muscarinic antagonist (LAMA), has demonstrated a similar efficacy and safety profile to open-label tiotropium in patients with moderate-to-severe chronic obstructive pulmonary disease (COPD). ${ }^{1}$ The GLOW5 study compared the efficacy and safety of glycopyrronium with blinded tiotropium.

Methods In this multicentre, 12-week, blinded study, patients $\geq$ 40 years with moderate-to-severe COPD (post-bronchodilator $\mathrm{FEV}_{1} \geq 30 \%$ and $<80 \%$ of the predicted normal, post-bronchodilator $\mathrm{FEV}_{1} / \mathrm{FVC}<0.70$ ) and a smoking history of $\geq 10$ pack-years were randomised to glycopyrronium $50 \mu \mathrm{g}$ (via Breezhaler ${ }^{\circledR}$ device) or tiotropium $18 \mu \mathrm{g}$ (via HandiHaler ${ }^{\circledR}$ device). The primary objective was to demonstrate non-inferiority of glycopyrronium versus tiotropium for trough $\mathrm{FEV}_{1}$ at Week 12 (non-inferiority margin: $-50 \mathrm{~mL}$ ). Other endpoints included $\mathrm{FEV}_{1}$ area under the curve from 0 to 4 hours $\left(\mathrm{AUC}_{0-}\right.$ $4 \mathrm{hr}$ ) on Day 1, Transition Dyspnoea Index (TDI), St George's Respiratory Questionnaire (SGRQ), rescue medication use, exacerbation rate, safety and tolerability.

Results Of the 657 patients randomised, (glycopyrronium [n = 327]; tiotropium [ $\mathrm{n}=330]$; mean age: 63.5 years, mean post-bronchodilator $\mathrm{FEV}_{1}: 53.5 \%$ predicted), 95.9\% completed the study. Glycopyrronium demonstrated non-inferiority to tiotropium for trough $\mathrm{FEV}_{1}$ at Week 12 (Least Squares Mean $[\mathrm{LSM}]=1.41 \mathrm{~L}$ for both the groups; 95\% confidence interval [CI]: $-0.032,0.031 \mathrm{~L})$. Glycopyrronium had a rapid onset of bronchodilation in the morning as demonstrated by a higher $\mathrm{FEV}_{1} \mathrm{AUC}_{0-4 \mathrm{hr}}$ on Day 1 compared to tiotropium (LSM treatment difference $[\mathrm{Td}]=58 \mathrm{~mL} ; \mathrm{p}<0.001)$. At Week 12, TDI total score $(\mathrm{Td}=-0.188 ; \mathrm{p}=0.385)$, SGRQ total score $(\mathrm{Td}=0.65 ; \mathrm{p}=0.488)$ and percentage of days with no rescue medication use $(\mathrm{Td}=-1.5 ; \mathrm{p}=0.528)$ were comparable between the groups. No significant treatment difference was observed with respect to rate of moderate/severe COPD exacerbations per year (glycopyrronium 0.38 versus tiotropium 0.35 [rate ratio $=1.10,95 \%$ CI: $0.62,1.93] ; \mathrm{p}=0.754$ ). Overall, the incidence of adverse events was similar in the glycopyrronium $(40.4 \%)$ and tiotropium (40.6\%) groups.

Conclusion Glycopyrronium and blinded tiotropium showed similar improvements in lung function, dyspnoea, health status, exacerbation rate and rescue medication use, with a similar safety and tolerability profile. Onset of bronchodilation with glycopyrronium was significantly more rapid following the first dose.

\section{REFERENCE}

1. Kerwin, E. et al. Eur Resp J 2012;40:1106-1114.

\section{P234 QVA149 ONCE DAILY IMPROVES LUNG FUNCTION, DYSPNOEA AND HEALTH STATUS INDEPENDENT OF PRIOR MEDICATIONS AND DISEASE SEVERITY: THE SHINE STUDY}

${ }^{1} \mathrm{KR}$ Chapman, ${ }^{2} \mathrm{ED}$ Bateman, ${ }^{3} \mathrm{~N}$ Gallagher, ${ }^{4} \mathrm{H} \mathrm{Hu},{ }^{4} \mathrm{D}$ Banerji; ${ }^{1}$ Asthma and Airway Centre, University Health Network, Toronto Western Hospital, Toronto, Canada; ${ }^{2}$ Department of Medicine, University of Cape Town, Cape Town, SA; ${ }^{3}$ Novartis Horsham Research Centre, West Sussex, UK; ${ }^{4}$ Novartis Pharmaceuticals Corporation, East Hanover, NJ, USA

\subsection{6/thoraxjnl-2013-204457.386}

Introduction QVA149 is a novel, inhaled, once-daily, fixed-dose combination of the long-acting $\beta_{2}$-agonist (LABA) indacaterol and the long-acting muscarinic antagonist (LAMA) glycopyrronium (NVA237) in development for the maintenance treatment of chronic obstructive pulmonary disease (COPD). The SHINE study compared the effects of QVA149 $110 / 50 \mu \mathrm{g}$, indacaterol $150 \mu \mathrm{g}$, glycopyrronium $50 \mu \mathrm{g}$, tiotropium $18 \mu \mathrm{g}$ and placebo in 
Abstract P234 Table 1. Lung function, dyspnoea and health status improvements in QVA149 vs placebo subgroup analyses based on prior medicationuse and disease severity.

\begin{tabular}{|c|c|c|c|c|}
\hline \multirow[b]{2}{*}{1} & \multicolumn{4}{|c|}{ LSM (SE) treatment difference of QVA149 vs placebc } \\
\hline & $\begin{array}{l}\text { FEV }_{1} \\
\text { AUC }_{5 \text { min-4h }}(\mathrm{L})\end{array}$ & $\begin{array}{l}\text { Trough } \\
\mathrm{FEV}_{1}(\mathrm{~L})\end{array}$ & $\begin{array}{l}\text { TDI } \\
\text { total } \\
\text { score }\end{array}$ & $\begin{array}{l}\text { SGRQ } \\
\text { total } \\
\text { score }\end{array}$ \\
\hline
\end{tabular}

Prior medication use

\begin{tabular}{|c|c|c|c|c|}
\hline $\begin{array}{l}\beta \text {-agonist plus } \\
\text { steroid }\end{array}$ & $0.34(0.030)^{* * *}$ & $0.19(0.030)^{\star * *}$ & $1.21(0.406)^{\star * *}$ & $-4.09(1.705)^{*}$ \\
\hline LABA & $0.36(0.059)^{* * *}$ & $0.25(0.058)^{\star * *}$ & $0.71(0.798)^{\mathrm{ns}}$ & $-0.34(3.103)^{\mathrm{ns}}$ \\
\hline LAMA & $0.33(0.028)^{\star * *}$ & $0.22(0.029)^{\star * *}$ & $1.48(0.443)^{* * *}$ & $-5.94(1.770)^{* *}$ \\
\hline SABA & $0.37(0.032)^{* * *}$ & $0.22(0.031)^{* * *}$ & $1.29(0.430)^{* *}$ & $-3.10(1.780)^{\mathrm{ns}}$ \\
\hline SAMA & $0.30(0.074)^{* * *}$ & $0.18(0.073)^{*}$ & $2.27(1.135)^{*}$ & $-3.24(4.495)^{\mathrm{ns}}$ \\
\hline $\begin{array}{l}\beta \text {-agonist plus } \\
\text { anticholinergic }\end{array}$ & $0.31(0.075)^{* * *}$ & $0.08(0.079)^{\mathrm{ns}}$ & $1.13(1.222)^{\mathrm{ns}}$ & $-4.66(4.935)^{\mathrm{ns}}$ \\
\hline None & $0.30(0.033)^{* \star *}$ & $0.17(0.034)^{\star * *}$ & $0.97(0.500)^{\mathrm{ns}}$ & $-2.30(2.198)^{\mathrm{ns}}$ \\
\hline COPD severity & & & & \\
\hline Moderate & $0.37(0.021)^{* * *}$ & $0.24(0.021)^{* * *}$ & $1.17(0.294)^{* * *}$ & $-2.74(1.257)^{*}$ \\
\hline Severe & $0.26(0.031)^{* * *}$ & $0.12(0.031)^{\star * *}$ & $1.00(0.433)^{*}$ & $-3.77(1.840)^{*}$ \\
\hline
\end{tabular}

${ }^{* * *} P<0.001 ;{ }^{* *} P<0.01 ;{ }^{*} P<0.05$; ns, non-significant

LSM, least squares mean; SABA, short-acting $\beta_{2}$-agonist; SAMA, short-acting muscarinic antagonist; $S E$, standard error

patients with COPD. ${ }^{1}$ Here, we present the data on improvements in lung function (forced expiratory volume in 1 second area under the curve $\left[\mathrm{FEV}_{1} \mathrm{AUC}_{5}\right.$ min-4 $\left.\mathrm{h}\right]$ and trough $\mathrm{FEV}_{1}$ ), transition dyspnoea index (TDI) and St George's Respiratory Questionnaire (SGRQ - total score) by prior medication use and COPD disease severity subgroups.

Methods In this 26-week, multicentre, double-blind, parallelgroup, placebo- and active-controlled (open-label tiotropium) study, patients aged $\geq 40$ years with moderate-to-severe COPD (post-bronchodilator $\mathrm{FEV}_{1} /$ forced vital capacity $(\mathrm{FVC})<0.7$ and $\mathrm{FEV}_{1} \geq 30 \%$ to $<80 \%$ predicted) and a smoking history of $\geq 10$ pack-years were randomised to receive once-daily QVA149, indacaterol, glycopyrronium, tiotropium or placebo $(2: 2: 2: 2: 1)$.
Results Of the 2144 patients (mean age 63.9 years; mean $\mathrm{FEV}_{1}$ post-bronchodilator $55.2 \%$ predicted) who were randomised (QVA149 $[n=475]$, indacaterol $[n=477]$, glycopyrronium [ $n=475]$, tiotropium $[n=483]$ and placebo $[n=234])$, $89.1 \%$ completed the study. QVA149 showed significant improvements in lung function, dyspnoea and health status compared with placebo in patient subgroups based on prior medication use and COPD disease severity (Table 1). Additionally, $\mathrm{FEV}_{1}$ $\mathrm{AUC}_{5}$ min-4 hWas significantly improved for QVA149 versus placebo $(p<0.001)$ regardless of the prior medication use and disease severity.

Conclusion With once-daily QVA149, significant improvements were seen in both moderate and severe COPD patients and independent of medications used before recruitment and randomisation into the SHINE study.

\section{REFERENCE}

1. Bateman et al. Dual bronchodilation with QVA149 versus single bronchodilator therapy: the SHINE study. Eur Respir J. 2013 May 30. [Epub ahead of print].

\section{P235 DUAL-BRONCHODILATION WITH ONCE-DAILY QVA149 IN PATIENTS WITH MODERATE-TO-SEVERE COPD: OVERVIEW OF THE IGNITE PROGRAM}

${ }^{1} \mathrm{D}$ Price, ${ }^{2} \mathrm{~K}$ Mezzi, ${ }^{3} \mathrm{MJ}$ Fedele, ${ }^{3} \mathrm{H}$ Chen, ${ }^{3} \mathrm{D}$ Banerij; ${ }^{1}$ Centre of Academic Primary Care, University of Aberdeen, Scotland, UK; ${ }^{2}$ Novartis Pharma $A G$, Basel, Switzerland; ${ }^{3}$ Novartis Pharmaceuticals Corporation, East Hanover, NJ, USA

\subsection{6/thoraxjn-2013-204457.387}

Introduction In patients with moderate-to-severe chronic obstructive pulmonary disease (COPD) whose symptoms are insufficiently controlled by monotherapy, current treatment strategies recommend the addition of a second bronchodilator with a different mechanism of action. Once-daily QVA149 is a dual bronchodilator combining the long-acting $\beta_{2}$-agonist indacaterol (IND) and long-acting muscarinic antagonist glycopyrronium (GLY). The IGNITE program comprises a series of randomised

\begin{tabular}{|c|c|c|c|c|c|c|c|}
\hline \multirow[b]{2}{*}{ Parameters } & \multirow[b]{2}{*}{ Study (N) } & & \multicolumn{4}{|c|}{ Treatment differences (QVA149 vs comparator) } & \multirow[b]{2}{*}{ SFC } \\
\hline & & & PBO & IND & GLY & TIO & \\
\hline \multirow[t]{7}{*}{ Lung function } & SPARK & Trough $\mathrm{FEV}_{1}, \mathrm{~mL}$ & - & - & $70^{* * *}$ & $60^{* * *}$ & - \\
\hline & (2224) & & & & & & \\
\hline & SHINE & & $200^{* * *}$ & $70^{* * *}$ & $90^{* \star *}$ & $80^{* \star \star}$ & - \\
\hline & $(2144)$ & $\mathrm{FEV}_{1} \mathrm{AUC}_{0-12 \mathrm{~h}}, \mathrm{~mL}$ & $330^{* * *}$ & $130^{* * *}$ & $130^{* * *}$ & $120^{* * *}$ & - \\
\hline & ILLUMINATE & & - & - & - & - & $140^{* * *}$ \\
\hline & $(523)$ & & & & & & \\
\hline & BLAZE & $\mathrm{FEV}_{1} \mathrm{AUC}_{0-4 h}, \mathrm{~mL}$ & $250^{* * *}$ & - & - & $90^{* * *}$ & - \\
\hline \multirow[t]{2}{*}{ Dyspnoea } & $(247)$ & TDI score & $1.37^{* * *}$ & - & - & $0.49^{*}$ & - \\
\hline & ILLUMINATE & & - & - & - & - & $0.76^{* *}$ \\
\hline Health status & SPARK & SGRQ score & - & - & $-2.07^{* * *}$ & $-2.69^{* * *}$ & - \\
\hline \multirow[t]{8}{*}{ Rate reduction of exacerbations, $\%$} & & Moderate-to-severe & - & - & 12 & 10 & - \\
\hline & & & & & RR $0.88^{*}$ & RR 0.90 & \\
\hline & & All & - & - & 15 & 14 & - \\
\hline & & & & & RR $0.85^{* * *}$ & RR $0.86^{* *}$ & \\
\hline & ILLUMINATE & Moderate-to-severe & - & - & - & - & 20 \\
\hline & & & & & & & RR 0.80 \\
\hline & & All & - & - & - & - & 31 \\
\hline & & & & & & & RR 0.69 \\
\hline
\end{tabular}

